\title{
DESENVOLVIMENTO LOCAL E MANEJO DA CAATINGA NO ASSENTAMENTO HIPÓLITO, EM MOSSORÓ/RN
}

\author{
E. D. G. Pereira ${ }^{1}$, E. M. A. Lima ${ }^{1}$, F. C. S. Souza ${ }^{2}$, M. S. M. Paulino ${ }^{3}$, J. B. Santos ${ }^{3}$, W. \\ G. Silva ${ }^{3}$, G. S. Bezerra ${ }^{3}$, M. L. S. Nóbrega ${ }^{3}$, D. A. M. Silva ${ }^{3}$, F. G. T. Filha ${ }^{3}$, M. A. \\ Oliveira $^{3}$, J. C. V. Martins ${ }^{3}$ \\ ${ }^{1}$ Bolsistas de Iniciação Científica do CEFET-RN/UNED \\ ${ }^{2}$ Orientador e Coordenador de Pesquisa no CEFET-RN/UNED; grec@cefetrn.br \\ ${ }^{3}$ Professores pesquisadores do Núcleo de Estudos de Ciências e Tecnologias Ambientais, \\ CEFET-RN/UNED; grec@cefetrn.br
}

Recebido em outubro de 2004 e Aceito em abril de 2005

\section{RESUMO}

Nas últimas décadas tem havido uma preocupação muito grande com o tipo de desenvolvimento que vem sendo implementado pelos governos. A partir daí, criou-se a noção de desenvolvimento sustentável, o qual se baseia em um crescimento econômico que seja acompanhado por eqüidade social e prudência ecológica. Em muitos projetos de assentamentos têm sido desenvolvidos pesquisas com o objetivo de analisar como vem se processando tais experiências. Nossa investigação teve como meta verificar os impactos sócio-ambientais trazidos a partir do uso da caatinga no assentamento Hipólito, no município de Mossoró, no Oeste do RN. Preocupou-nos saber se naquele projeto de assentamento tem ocorrido um desenvolvimento local, baseado em critérios de sustentabilidade. A metodologia empregada foi a realização de entrevistas com 29 assentados, o que corresponde a $20 \%$ da população total do assentamento, além de leituras de outros trabalhos e artigos de jornais. O trabalho está em fase de conclusão, porém a partir de estudos de campo, realizados no mês de agosto de 2004, podemos apresentar os seguintes resultados: quanto ao aspecto sócio-econômico, os assentados têm na agricultura de sequeiro a atividade econômica principal; a produtividade é baixa e a renda é complementada com "bicos", aposentadorias e/ou com o dinheiro advindo dos planos de assistência social do Governo Federal; a agricultura é realizada sem os devidos cuidados com o meio ambiente, e o desmatamento desordenado tem agravado ainda mais os problemas presentes no bioma caatinga, tais como salinização, a desertificação e o desaparecimento de espécies da fauna e da flora. Face ao exposto, podemos concluir que a realidade observada no assentamento aponta para a insustentabilidade sócio-econômica e ambiental naquela área.

Palavras-chave: sustentabilidade; caatinga; assentamento; desenvolvimento rural; desenvolvimento local. 


\section{DESENVOLVIMENTO LOCAL E MANEJO DA CAATINGA NO ASSENTAMENTO HIPÓLITO, EM MOSSORÓ/RN}

\section{INTRODUÇÃO}

Como resultado dos graves problemas ambientais advindos das políticas de desenvolvimento, uma questão que se tem colocado a partir das últimas décadas do século XX diz respeito à necessidade de um novo paradigma de desenvolvimento que tenha uma base social, econômica, cultural e ambiental mais sustentável. Logicamente, essa nova preocupação vai se constituindo lentamente e de maneiras muito distintas entre os vários agentes, indivíduos, governos, organizações internacionais, entidades da sociedade civil etc.

Foi como resultado dos debates realizados que criou-se a noção de desenvolvimento sustentável, o qual foi considerado pelo Relatório Brundtland, mais conhecido como Nosso Futuro Comum, como "aquele que atende às necessidades do presente sem comprometer a possibilidade de as gerações futuras atenderem a suas próprias necessidades". (Nosso Futuro Comum, 1991).

No setor agropecuário, um número crescente de profissionais, pesquisadores e produtores, devido a necessidade de um novo padrão produtivo como sucedâneo ao modelo de agricultura "moderna" ou "convencional" até então vigente, tem adotado as expressões agricultura sustentável e desenvolvimento rural sustentável. Apesar de haver uma grande quantidade de definições para explicar o que se entende por agricultura sustentável, em geral, elas incorporam os seguintes itens:

(a) manutenção a longo prazo dos recursos naturais e da produtividade agrícola; (b) mínimo de impactos adversos ao ambiente; (c) retornos financeiro-econômicos adequados aos agricultores; (d) otimização da produção das culturas com o mínimo de insumos químicos; (e) satisfação das necessidades humanas de alimentos e de renda; $e$ ( $f$ ) atendimento das necessidades sociais das famílias e das comunidades rurais". (Almeida, 1998)

No Brasil, os órgãos governamentais têm proposto a discussão sobre os novos rumos do desenvolvimento rural no País. O objetivo é a redução das desigualdades sociais e regionais por meio de novos mecanismos de geração de emprego e renda, reorientação na aplicação dos gastos públicos e maximização das potencialidades locais, haja vista que o conhecimento das especificidades locais possibilita o surgimento de soluções mais eficientes para as demandas sociais. Dessa forma, a Presidência da República e o Conselho da Comunidade Solidária, enfatiza o desenvolvimento local como "um novo modo de promover o desenvolvimento que possibilita o surgimento de comunidades mais sustentáveis, capazes de suprir suas necessidades imediatas; descobrir ou despertar suas vocações locais e desenvolver suas potencialidades específicas; e fomentar o intercâmbio externo aproveitando-se de suas vantagens locais” (citado por Flores \& Macêdo)

Objetivou-se nesse trabalho verificar os impactos sócio-ambientais trazidos a partir do manejo da caatinga no assentamento Hipólito, no município de Mossoró, Oeste do RN. 
Preocupou-nos saber se naquele projeto de assentamento tem ocorrido um desenvolvimento local, baseado em critérios de sustentabilidade.

\section{O Assentamento Hipólito: Origens}

O Projeto de Assentamento de Reforma Agrária da Fazenda Hipólito está localizado às margens da BR 304, a uma distância de 28 km de Mossoró e 242 km de Natal. A desapropriação da Fazenda Hipólito por interesse social, deu-se em 10 de outubro de 1986. Na época estava vigindo o I Plano Nacional de Reforma Agrária, no governo José Sarney. Após os trâmites legais, o INCRA emitiu a posse em 14 de maio de 1987 e criou o Projeto de Assentamento de Reforma Agrária da Fazenda Hipólito, em 09 de julho de 1987. A área do imóvel perfazia 6.726,40 ha. Para efeito de implantação do Projeto de Assentamento, foi desapropriada uma área de 4.864,60 ha. e distribuída 30 ha para 137 famílias. Desta forma, 15 ha são destinados para a produção familiar individual e os 15 restantes, para produção coletiva. (Oliveira \& Silva, 1995)

A partir dos recursos liberados pelo Governo Federal desde a sua criação, o assentamento Hipólito, atualmente, dispõe da seguinte infra-estrutura social e produtiva: 137 casas residenciais com energia, 4 poços tubulares (no total com uma vazão de $200 \mathrm{~m}^{3} / \mathrm{h}$ ), 1,3 km de rede elétrica, 2 cisternas (1 com 60 mil litros e outra com 1.100 litros), cercas perimetrais, 2 praças, 1 posto telefônico, 1 igreja, 2 armazéns, 2 galpões (com depósitos conjugados), 1 almoxarifado, 2 chafarizes, 4,64 km de adutora, 1 trator com implementos, equipamentos de irrigação (gotejadores), 1 estábulo, 2 caixas d’água (62 mil litros) e 1 escola de ensino fundamental.

\section{Caracterização Sócio-Econômica dos Assentados}

Antes de se estabelecerem no assentamento Hipólito, a maioria das famílias entrevistadas, 51,7\%, habitava na zona urbana de Mossoró e de cidades circunvizinhas. Entretanto, a maior parte delas, 58,6\%, informou que praticava atividades na zona rural desses municípios, o que demonstra o quanto são comuns as migrações periódicas dessas populações do espaço urbano para o rural e vice-versa. Na zona rural trabalhavam em lavouras de milho, feijão e algodão e eram principalmente meeiros na época da estação chuvosa.

Das 29 famílias entrevistadas, 79,3\% dos informantes são casados, sendo as famílias compostas, em média, por 6 ou mais pessoas (ver figura 1). Neste caso preferimos registrar aquelas famílias cujos filhos moram ainda junto com os pais, pois há muitos casos de famílias compostas apenas por idosos, tendo os filhos migrado para outros locais. 
Figura 1: Número de filhos por família

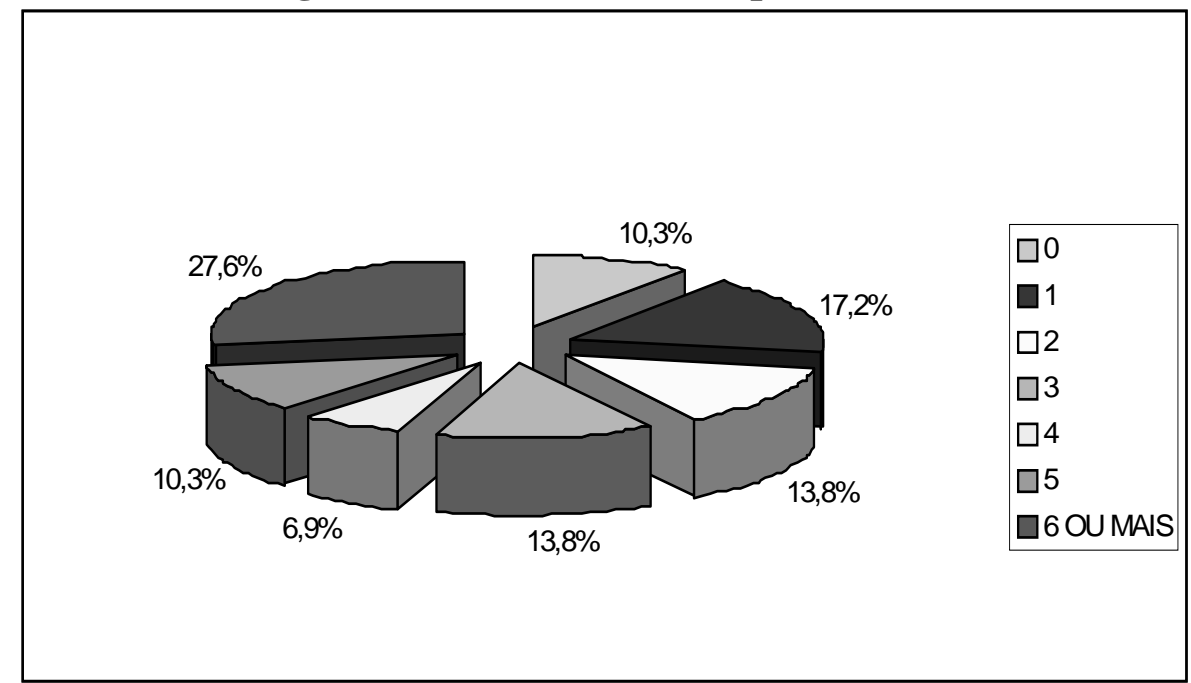

Quanto à escolaridade, a realidade do assentamento estudado não é muito diferente de outras situações vistas no meio rural brasileiro, principalmente o nordestino. A grande maioria, 72,4\%, tem apenas o ensino fundamental, geralmente incompleto, pois muitos pararam de estudar nas séries iniciais (ver figura 2). Observamos alguns casos de pessoas idosas que são analfabetas ou estão cursando a alfabetização solidária.

Figura 2: Escolaridade dos membros das famílias

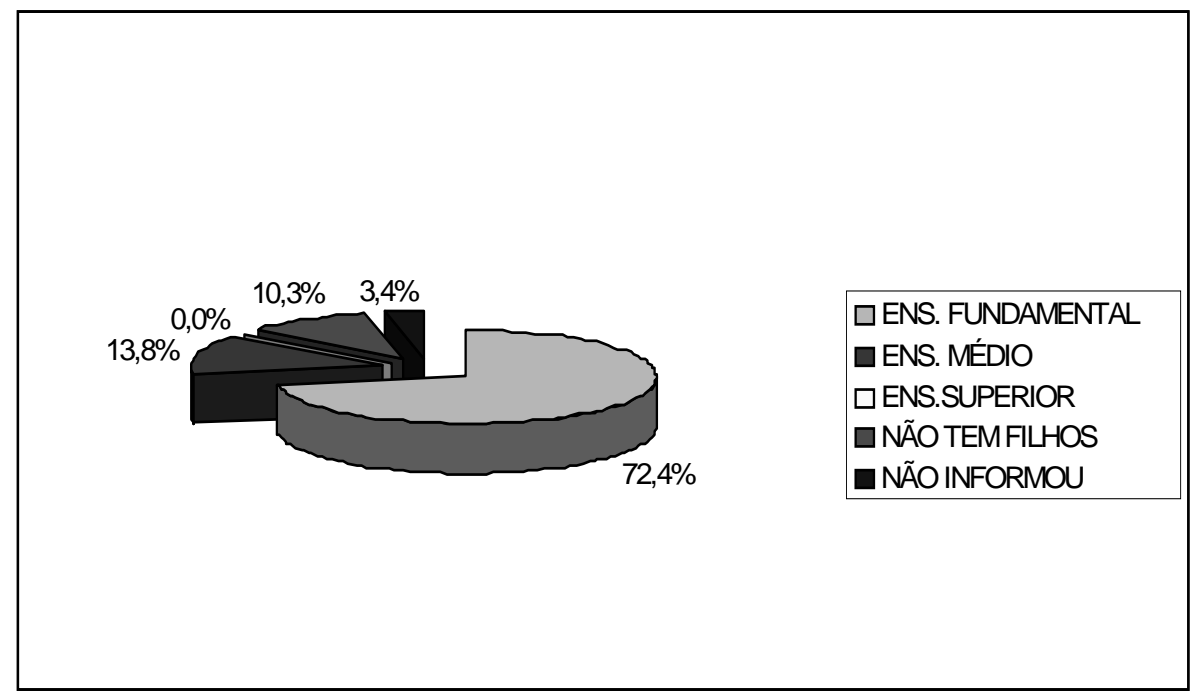

Caracterizar o rendimento atual das famílias pesquisadas foi uma das nossas maiores preocupações. A atividade econômica mais importante desenvolvida pelas famílias é a agricultura de sequeiro (51,7\%), de subsistência e praticada principalmente no lote individual. Como a maior parte da colheita já havia sido feita à época da pesquisa, agosto de 2004, muitos declararam não possuir produção. (ver figuras 3 e 4) No caso da cultura do sorgo, os assentados tiveram acesso a créditos, mas reclamam da falta de compradores e dos baixos preços que conseguem na venda do saco de $60 \mathrm{~kg}$, em média $\mathrm{R} \$ 12,00$, o qual não é compensador uma vez que compraram a semente por $\mathrm{R} \$ 5,00 \mathrm{o} \mathrm{kg}$. Em anos 
anteriores os assentados do Hipólito desenvolviam a produção do melão, em "terceirização" com empresas de exportação como a Nolem. O fracasso da última produção, em 2002, desestimulou a continuidade do projeto no assentamento. (Souza, 2002)

Figura 3: Tipos de produção agrícola

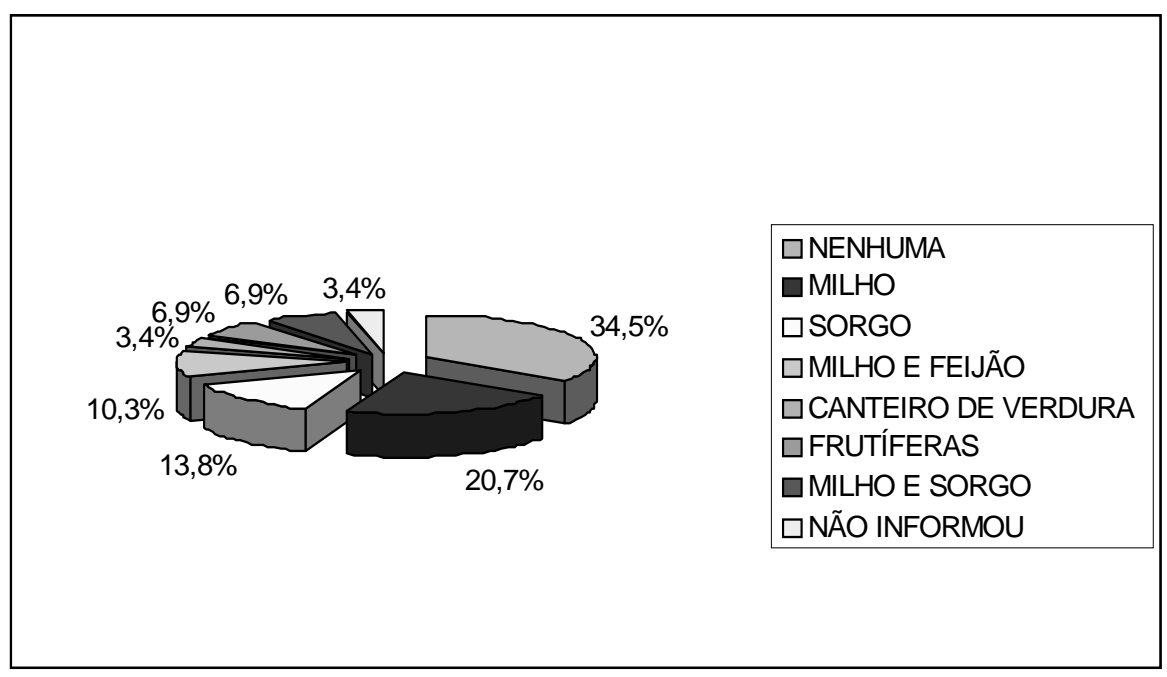

Figura 4: Destino da produção agrícola dos assentados

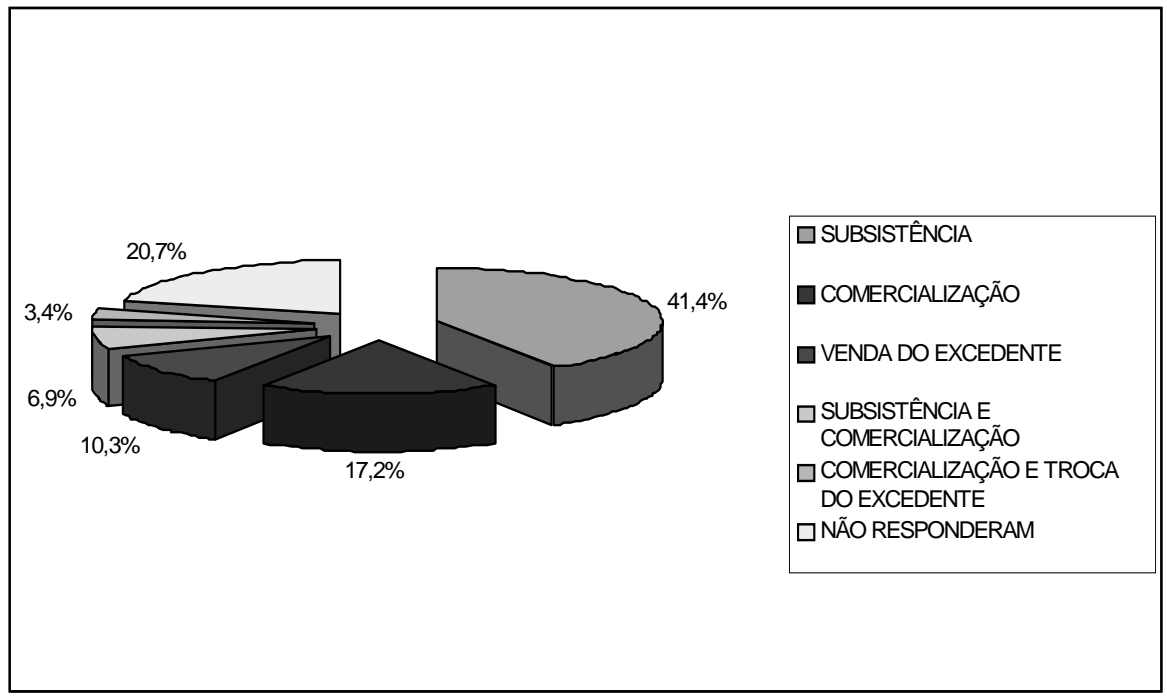

Apesar da agricultura ser a atividade mais importante para os moradores do Hipólito, ela não é a única fonte de renda para um número considerável de famílias, merecendo destaque as atividades não-agrícolas, as aposentadorias e as rendas provenientes de programas de assistência do governo, conforme podemos ver na figura 5. 
Figura 5: Outras fontes de renda das famílias

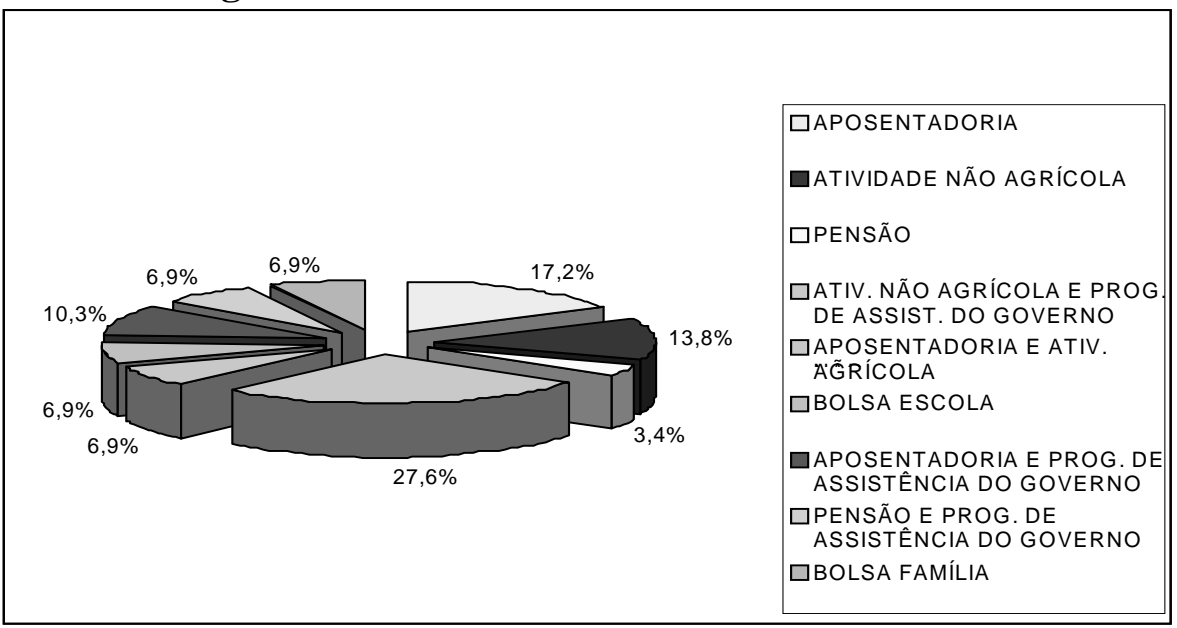

Os assentados também desenvolvem a criação de animais como eqüinos, ovinos, caprinos, muares e aves (galinhas, patos, guinés). Segundo os informantes, essa produção não tem como destino principal a comercialização. Porém, muitos deixam claro que ocorrem vendas desses animais e de seus derivados (ovos e leite) quando surge uma necessidade maior como problemas de saúde na família, por exemplo.

Como já nos referimos anteriormente, os moradores do Hipólito têm na agricultura a sua principal renda, porém alguns informaram que praticam atividades extrativistas como a extração de mel para a venda na zona urbana, em média por R\$ 4,00, o litro. Além disso, muitos trabalham na "limpeza de castanhas", em suas casas, para empresas que vendem esse produto. A família recebe $\mathrm{R} \$ 0,45$ por cada quilo de castanhas, sendo o pagamento quinzenal e podendo chegar a $\mathrm{R} \$ 60,00$.

Com base no exposto, ao serem questionados quanto à renda média da família, incluindo aí atividades agrícolas, não-agrícolas, aposentadorias e programas de assistência do governo, a realidade que observamos pode ser expressa na figura 6 .

Figura 6: Renda média das famílias (por salários mínimos)

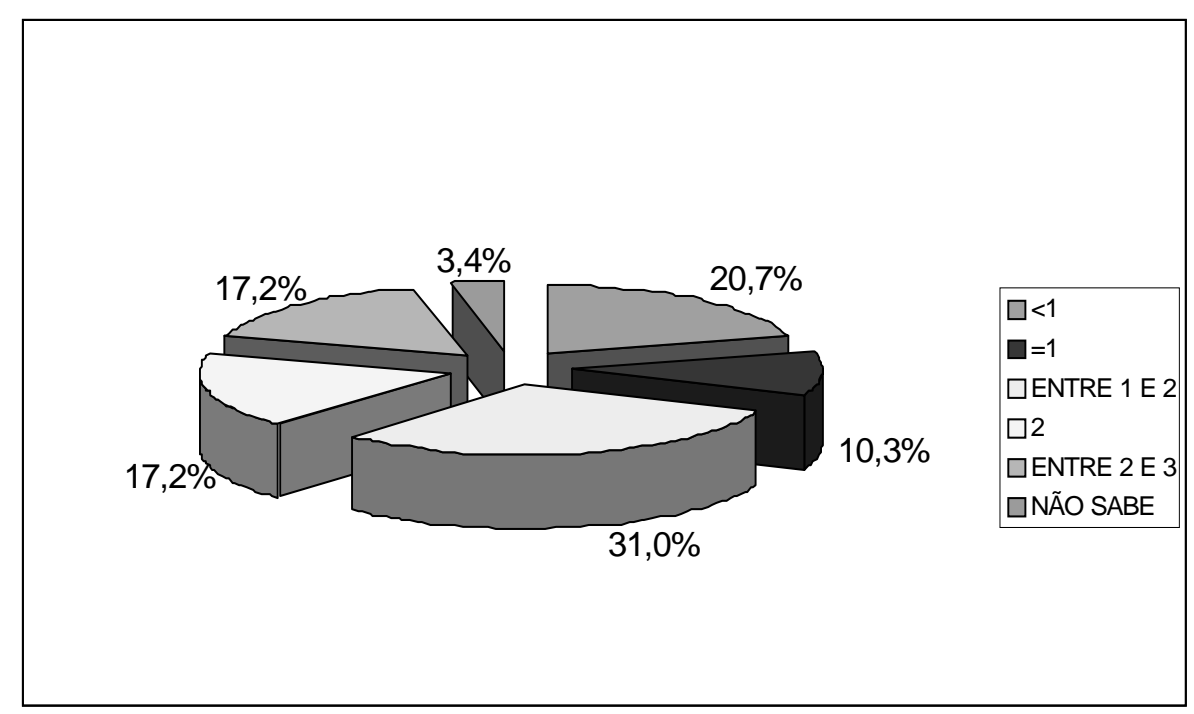


Quanto aos bens de consumo, nas casas foram encontrados fogão a gás (82,8\%), televisão (79,3\%) geladeira (65,5\%), bicicleta (65,5\%), aparelho de som (58,6\%), antena parabólica $(44,8 \%)$. Houve apenas dois casos de assentados possuidores de carro e de motos.

\section{A Utilização dos Recursos Naturais e os Problemas Ambientais}

O assentamento Hipólito está localizado no sertão do Rio Grande do Norte, inserido, portanto, dentro dão bioma caatinga. Toda a produção econômica é realizada utilizando os recursos naturais desse ecossistema. Uma primeira questão que nos preocupou foi quanto ao desmatamento. Isto se deve em primeiro lugar, ao fato do Rio Grande do Norte ser um estado que se encontra inserido dentro de uma área de desertificação, daí a sua inserção no Plano Nacional de Desertificação; e, em segundo lugar, porque, de acordo com Francelino (2000), o Hipólito é o assentamento do Semi-Árido norte-rio-grandense com o maior processo de degradação na cobertura florestal. O desmatamento cresceu mais de $1000 \%$. "Praticamente não há mais mata densa na reserva, e o pouco que ainda resta no assentamento representa somente 13,2\% da sua área total", assegura o autor.

No período em que estivemos realizando a pesquisa de campo, os entrevistados negaram que cortavam a vegetação para a venda, apesar de afirmarem que outras pessoas, que não identificaram, praticam a venda de madeiras. Segundo os entrevistados, suas famílias só retiravam a madeira para o consumo doméstico e para a construção de cercas (ver figura 7). Entretanto, em pesquisa no assentamento em anos anteriores, Souza (2002) observou que a extração de lenha destina-se também às panificadoras de Mossoró e às cerâmicas de Assu. As estacas e mourões eram vendidos, à época, por respectivamente $\mathrm{R} \$ 0,50$ e $\mathrm{R} \$$ 1,50, para a construção de cercas. O corte era feito com a conivência dos demais assentados, pois compreendiam essa prática como causada pelas necessidades econômicas das famílias.

Para a nossa pesquisa, os assentados asseguraram que a retirada da madeira se dá semanalmente $(41,4 \%)$ e diariamente $(13,8 \%)$. Outros afirmaram que retiram lenha esporadicamente quando vai consertar ou fazer cercas.

Figura 7: Destino da madeira extraída no assentamento

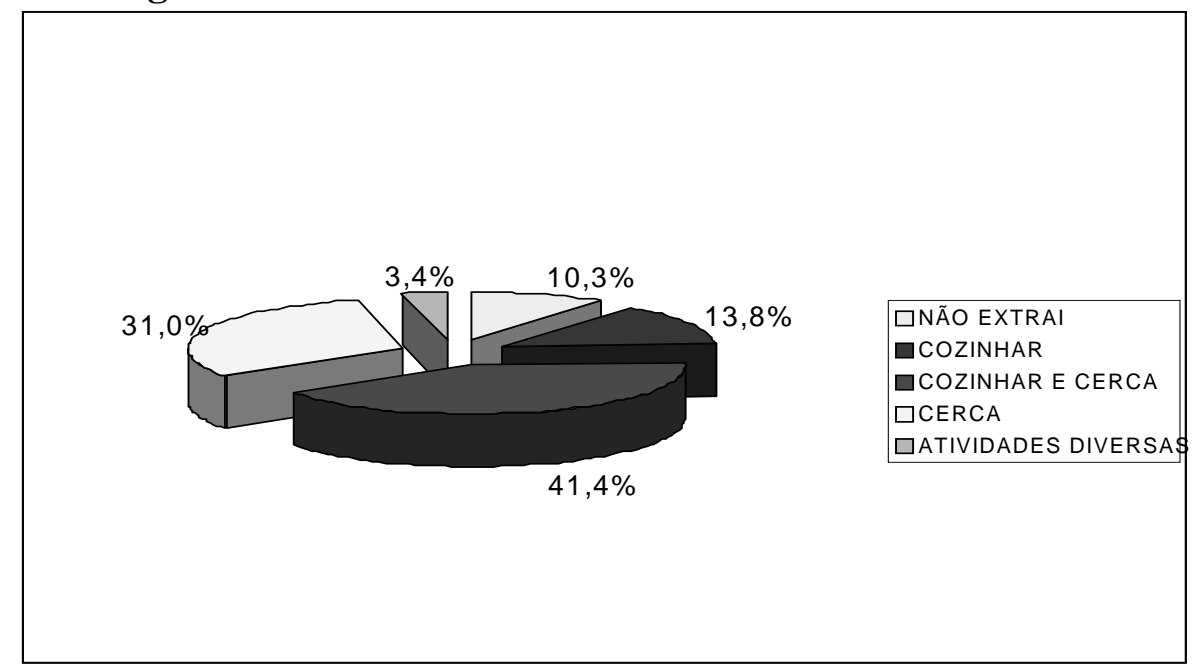

Vivenciamos ao longo da pesquisa que os assentados não se preocupam diretamente com os problemas ambientais advindos de sua produção. Podemos observar de acordo com a 
figura 8 que mais da metade dos entrevistados desconhecem que a pecuária e agricultura utilizadas de forma intensa e com o uso de técnicas tradicionais ultrapassadas como a queimada, a falta de observação do vento para o plantio, e a declividade do solo, dentre outros, podem acarretar problemas graves de degradação ambiental.

\section{Figura 8: Agricultura/pecuária traz algum problema ambiental}

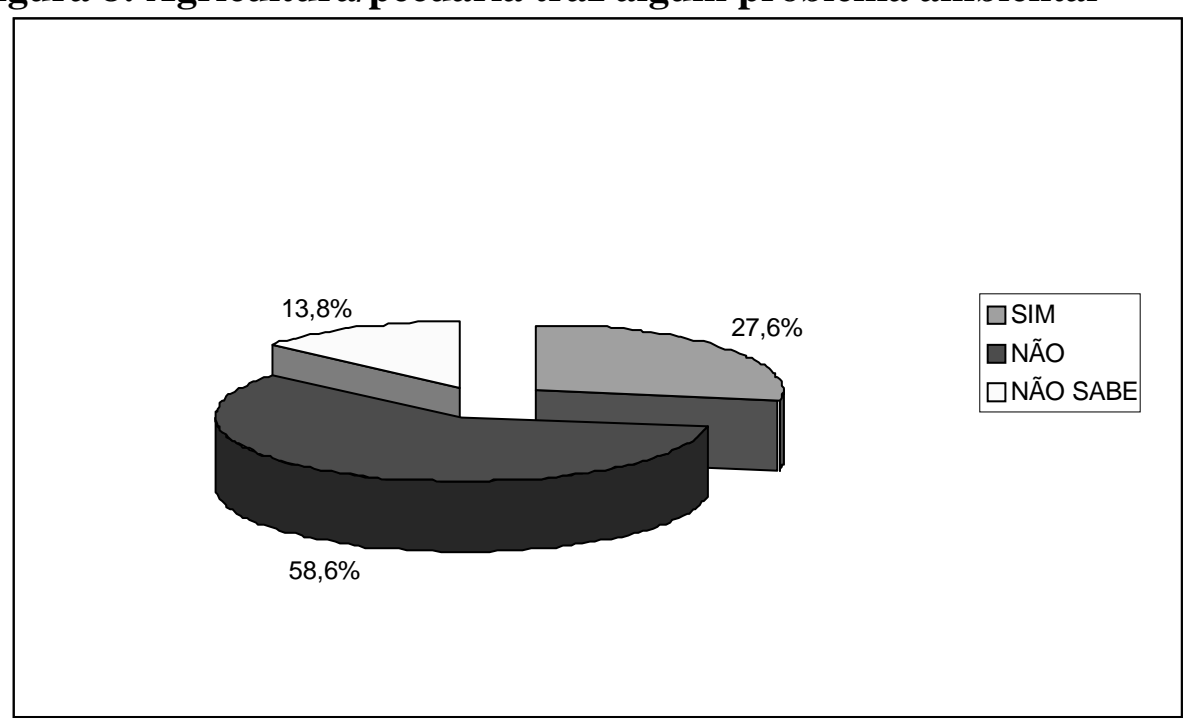

A falta de instrução e de capacitação no uso de novas técnicas agrícolas levam os assentados a perder gradativamente seu maior bem, a terra, e para ser mais exato, o solo. Para comprovarmos esta situação observe a figura 9. O uso de uma técnica não muito comum entre os produtores que é a proteção do solo, com objetivo de evitar perdas de sua camada superficial, que é a mais fértil, não chega a ser conhecida por grande parte dos entrevistados. O uso do solo indevidamente deverá trazer graves problemas para a produção, que já não apresenta bons resultados. O risco de salinização do solo e sua laterização são uma evidência que podemos constatar com as análises feitas em laboratório credenciado.

Figura 9: Uso de medidas de proteção do solo para o plantio

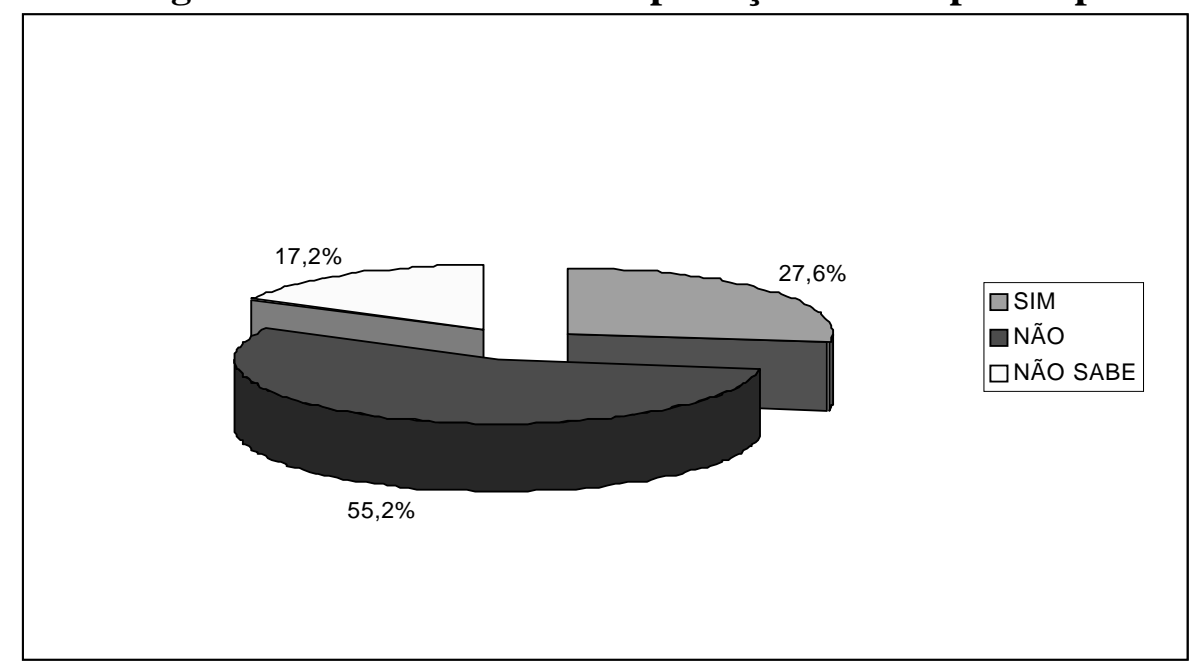

Dentre aqueles que declararam que praticam técnicas de proteção do solo, a grande maioria (75\%) utiliza a incorporação de resto de culturas, enquanto que $25 \%$ fazem opção pela prática da cobertura morta. Essas práticas são válidas, porém não podem ser empregadas 
sem o devido conhecimento técnico. A incorporação de cobertura morta (o adicionamento de outras culturas no solo, como por exemplo, palhas de carnaúba), e a utilização de restos de culturas como forma de agregar ao solo nutrientes advindos da decomposição e da matéria orgânica instalada, poderá, em parte, reverter o quadro nutricional dos compostos da micro-fauna, mas, no entanto, poderá trazer outros problemas para as culturas posteriores, tais como, a proliferação de pragas caso não se tenha o devido controle dos produtos que foram usados e que culturas estão sendo intercaladas.

Para produzir bem, a terra, assim como os seres humanos, precisa de descanso. A prática do pousio não é usada dentre a grande maioria dos assentados ou é usada inadequadamenrte, como podemos verificar na figura 10 e 11. A definição de terras para o plantio com sua localização exata e qual cultura praticada é fundamental para a aplicação desta técnica, já que a terra permanecerá em descaso em média de dois anos e isso foi pouquíssimo observado. Assim, para a prática correta do repouso do solo faz-se necessário um levantamento histórico das culturas praticadas e quais terras utilizadas, como também as que já passaram por essa técnica.

Figura 10: Uso de técnicas de repouso do solo

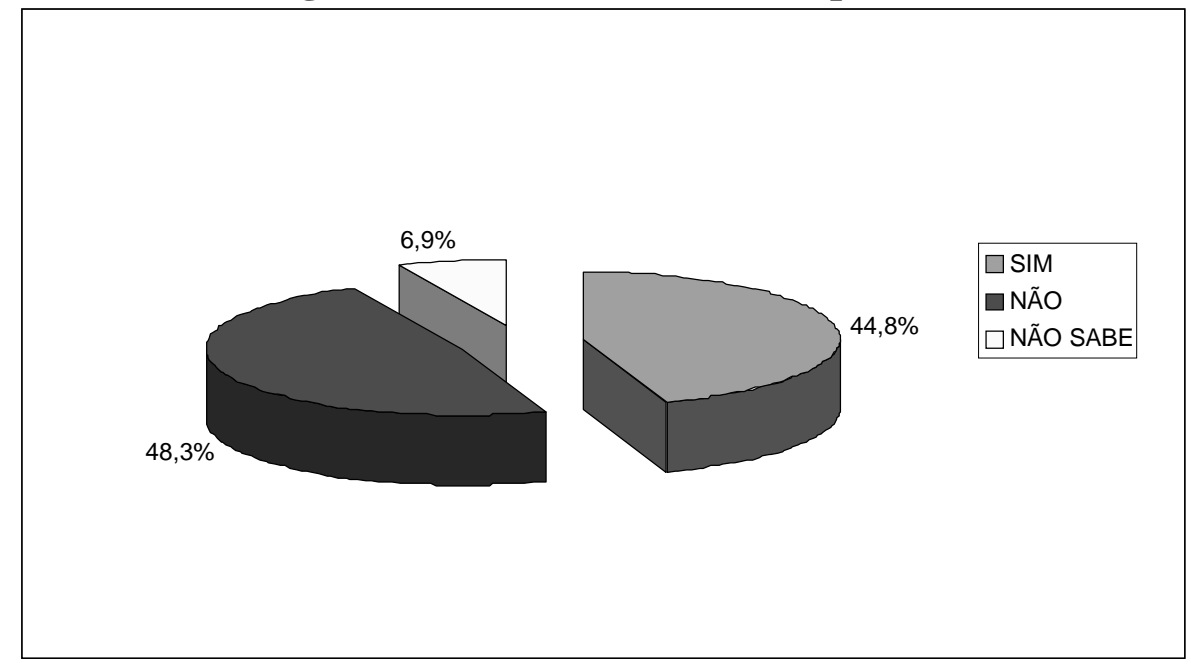

Figura 11: Período em que mantém a terra em repouso

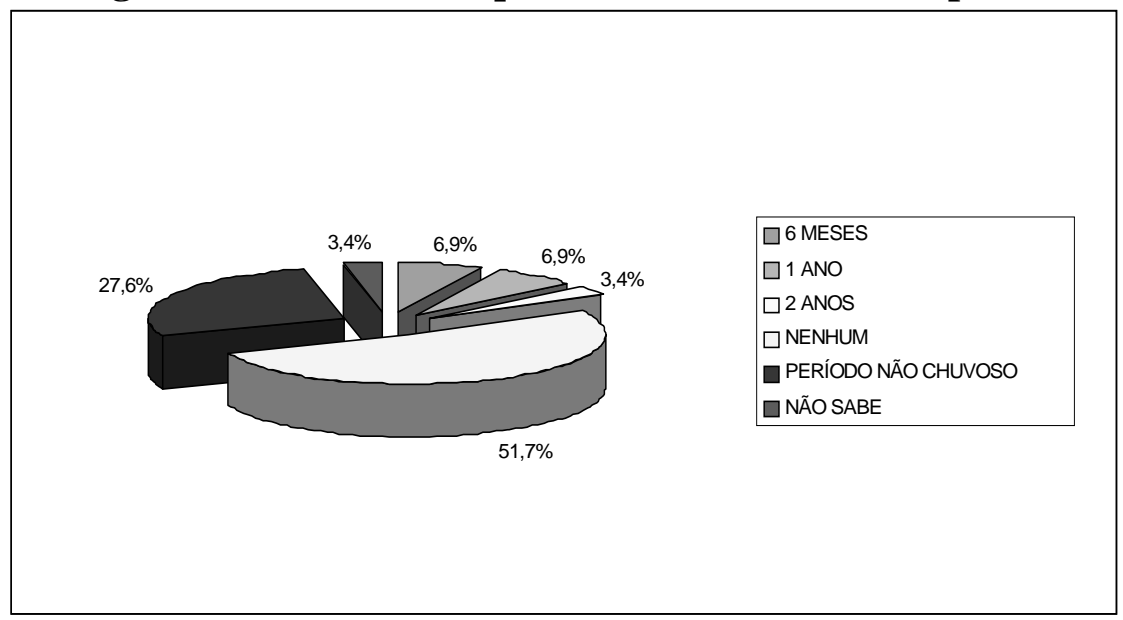


Outro método importante para a preservação da fertilidade do solo é a de rotação de cultura. Embora a maioria dos informantes não a utilizem, ela é exercida no assentamento por quase metade dos entrevistados (44,8\%). Todavia as culturas utilizadas normalmente são gramíneas (milho e sorgo), o que, de certa forma, torna ineficiente o uso dessa prática, já que não haverá deposição de nutrientes no solo. O uso de uma outra variedade, ou seja, uma leguminosa melhoraria o emprego dessa técnica. Estes dados comprovam o total desconhecimento dos assentados do uso da prática de rotação de cultura. (Ver figura 12)

Figura 12: Prática de rotação de culturas

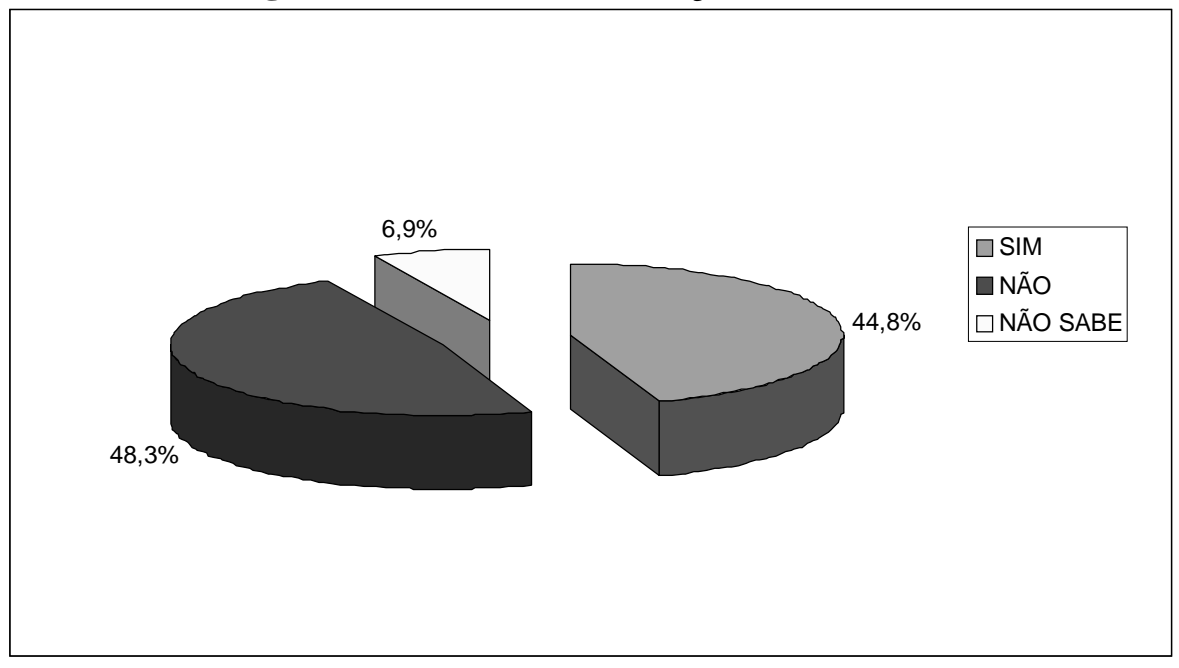

O uso de agroquímicos é comum no assentamento Hipólito, apesar de já ter sido mais aplicado na época em que plantavam melão para empresas de exportação desse produto, como assegura Souza (2002). Hoje, como essa cultura não está sendo desenvolvida no assentamento, apenas $17,2 \%$ dos entrevistados afirmaram que usam adubos químicos, enquanto 20,7\% usam adubos orgânicos. A maior parte não usa nenhum adubo, muitos vezes porque supõem que a terra já está fértil devido ao uso de fertilizantes na época do cultivo do melão.

O uso de agroquímicos é feito sem a observância de orientação técnica. As embalagens de agrotóxicos, fertilizantes e adubos usados, muitas vezes são reutilizadas para outros fins, como carregar água e armazenagem de alimentos ou grãos, como foi verificado in loco. Algumas são incineradas, enterradas ou simplesmente são jogadas a céu aberto não havendo controle algum, gerando uma grande quantidade de resíduos e desobedecendo a legislação vigente quanto à proteção ambiental. Além disso, sabemos que o emprego indiscriminado de agroquímicos traz como efeito graves problemas à saúde humana, ao solo, à água, enfim, ao ecossistema como um todo.

O uso de algum tipo de EPI’s (Equipamento de Proteção Individual), como máscara, luvas ou botas, ocorre entre a maioria dos informantes (41,4\%), porém isso é feito de forma inadequada, ademais alguns chegam a lavar as roupas utilizadas na aplicação de venenos em sua própria casa, no local de trabalho, em água corrente ou até em máquina de lavar. 


\section{CONCLUSÃO}

A realidade que percebemos no assentamento Hipólito não é diferente daquela vivida pela maioria dos assentamentos de reforma agrária no sertão do Rio Grande do Norte e de estados nordestinos: a pobreza, o desemprego e a ausência de projetos que garantam emprego e renda, e que manteria o trabalhador rural no campo.

As condições de vida das famílias são precárias. Muitos entrevistados (20\%), têm uma renda inferior a um salário mínimo, sobrevivendo melhor aquelas famílias que recebem aposentadoria ou algum dinheiro proveniente de programas assistenciais do Governo Federal. Falta trabalho para todos os membros das famílias, motivo pelo qual muitos migram para as cidades vizinhas ou para o Sudeste do país. Os projetos, mesmo tendo recebido financiamento, como o do sorgo, cultivado em 2004, não têm logrado êxito pois muitos não conseguem vender o produto ou, quando conseguem, vende-o a preços irrisórios.

A falta de perspectiva de renda faz com que haja uma maior intervenção nos recursos naturais da caatinga, uma vez que não podemos divorciar as questões ambientais dos problemas sócio-econômicos. A caatinga vem sofrendo muito nos últimos anos com o desmatamento tanto para o desenvolvimento de projetos de caprinocultura e de melão, por exemplo, como pela extração descontrolada de madeira para o uso doméstico, para a construção de cercas ou para a venda - embora muitos neguem que a pratiquem. Ao rareamento de algumas espécies da flora, some-se a caça predatória. Foi comum ouvirmos assentados dizerem que já não vêem com freqüência animais tão comuns na caatinga como preás, tejus, tatus, dentre outros.

Além desses problemas sócio-ambientais observamos um outro, que é a utilização de técnicas inapropriadas ou que podem ser prejudiciais se feitas sem os devidos conhecimentos técnicos, como a irrigação - usada principalmente na época do cultivo do melão, e que pode salinizar o solo, processo este já presente no assentamento -, e o uso de agroquímicos, os quais podem trazer sérios danos ao homem e ao ecossistema como um todo.

Pode-se concluir, portanto, que no assentamento Hipólito não há um desenvolvimento rural sustentável. O manejo da caatinga é feito sem os devidos cuidados ambientais, o que tem causado a destruição de espécies da fauna e flora, trazendo problemas para as futuras gerações. Como também os projetos desenvolvidos naquela área de reforma agrária não caminham para a atenuação da pobreza rural, pois não geram emprego e renda a contento.

\section{BIBLIOGRAFIA}

ALMEIDA, Jalcione. Da ideologia do progresso à idéia de desenvolvimento (rural) sustentável . In: e NAVARRO, Zander. (org.) Reconstruindo a agricultura: idéias e ideais na perspectiva do desenvolvimento rural sustentável. 2. ed. Porto Alegre: Ed. Universidade/UFRGS, 1998. p. 33-55.

COMISSÃO MUNDIAL SOBRE DESENVOLVIMENTO E MEIO AMBIENTE. Nosso futuro comum. 2. ed. Rio de Janeiro: Fundação Getúlio Vargas, 1991. 
FLORES, Murilo X. e MACEDO. Manoel M. C. Novos rumos do desenvolvimento rural. Disponível em: < http://www.eco.unicamp.br/projetos/sober4-99.html> Acesso em: 22 jan. 2001.

FRANCELINO, Márcio R. Caracterização e avaliação das áreas de reservas de recursos em projetos de assentamentos no Semi-Árido norte-rio-grandense. Viçosa/MG, 2000. Disponível em: http://www.solos.ufv.br/neput Acesso em 30 out. 2001.

OLIVEIRA, Maria das G. A. e SILVA, Paulo. S. G. Reestruturação da Associação do Projeto de Assentamento de Reforma Agrária da Fazenda Hipólito - APARAHI. 1995. Monografia (Especialização em Associativismo) - Departamento de Educação, Universidade Federal Rural de Pernambuco/ Universidade de Sherbrooke (Canadá), Recife, 1995.

SOUZA, Francisco C. S. A integração produtiva na cultura do melão e os desafios para a sustentabilidade da agricultura familiar: o caso do assentamento Hipólito, em Mossoró-RN. 2002. 101 f. Dissertação (Mestrado em Desenvolvimento e Meio Ambiente) - Departamento de Geografia, Universidade do Estado do Rio Grande do Norte, Mossoró, 2002. 